\title{
Stem Cells, Retinal Ganglion Cells and Glaucoma
}

\author{
Valentin M. Sluch ${ }^{\mathrm{a}, \mathrm{b}} \cdot$ Donald J. Zack ${ }^{\mathrm{a}, \mathrm{c}-\mathrm{f}}$ \\ ${ }^{a}$ Ophthalmology, Wilmer Eye Institute, ${ }^{b}$ Biochemistry, Cellular and Molecular Biology Graduate Program, \\ Departments of ${ }^{\mathrm{C}}$ Molecular Biology and Genetics, and ${ }^{\mathrm{d}}$ Neuroscience, ${ }^{\mathrm{e}}$ Institute of Genetic Medicine, Johns \\ Hopkins University School of Medicine, Baltimore, Md., USA; ${ }^{f}$ Institut de la Vision, Université Pierre et Marie \\ Curie, Paris, France
}

\begin{abstract}
Retinal ganglion cells (RGCs) represent an essential neuronal cell type for vision. These cells receive inputs from light-sensing photoreceptors via retinal interneurons and then relay these signals to the brain for further processing. RGC diseases that result in cell death, e.g. glaucoma, often lead to permanent damage since mammalian nerves do not regenerate. Stem cell differentiation can generate cells needed for replacement or can be used to generate cells capable of secreting protective factors to promote survival. In addition, stem cell-derived cells can be used in drug screening research. Here, we discuss the current state of stem cell research potential for interference in glaucoma and other optic nerve diseases with a focus on stem cell differentiation to RGCs.
\end{abstract}

(C) 2014 S. Karger AG, Basel

The retinal degenerative disorders encompass a large group of diseases that can lead to blindness. One of the most common of these diseases is glaucoma, an optic neuropathy marked by axonal damage and progressive loss of retinal ganglion cells (RGCs) that over time can result in permanent vision loss [1]. Unfortunately, due to the gradual loss of vision in glaucoma, patients can be unaware that they even have the disease until significant RGC loss has already occurred. Glaucoma is a multifactorial disorder, with increased intraocular pressure (IOP) being the best characterized risk factor, and the only one that is currently amenable to treatment [2]. IOP can be lowered with eye drops, laser treatment, and other forms of surgery. However, lowered IOP does not always prevent further degeneration, and glaucomatous optic nerve damage can arise and progress even in individuals who have never had documented increased IOP. Thus, there is a need to develop additional therapeutic strategies, beyond IOP lowering, to slow down, and ideally, prevent progressive RGC damage in glaucoma. One such approach is neuroprotection [3-5]. Neuroprotection focuses on improving survival and function of neurons through mechanisms that are generally downstream from the initial neuronal insult. Additionally, beyond neuroprotection, there is a need to develop approaches to help restore vision for patients with glaucoma and other forms of optic nerve disease who have already lost vision due to RGC damage. 
Stem cell biology holds great promise to aid and expedite several major areas of glaucoma research and therapeutic development. These areas include studies of the mechanisms of RGC injury and cell death, identification and testing of neuroprotective drugs, and development of cellbased therapies for glaucoma and other forms of optic nerve disease. The development of stem cell-derived RGCs suitable for stem cell-based therapy holds the potential to someday make possible the restoration of vision to patients who have already lost vision from optic nerve damage. In this chapter, we will discuss the current status of RGC stem cell research.

Stem cell differentiation is a complex and time-consuming process. In general, embryonic stem cells (ESCs) follow the natural developmental process. Since these cells are pluripotent, they carry the capacity to differentiate into any cell found in the body. If allowed to differentiate nonspecifically, these cells tend to differentiate into a highly heterogeneous mixture of cell types as highlighted by the propensity of ESCs to form teratomas, tumors consisting of all three germ layers, when injected into immunodeficient mice [6]. However, using knowledge gained from developmental studies as well as trial and error experimentation, researchers have been able to modify culture conditions in order to direct stem cell differentiation toward a particular path. In this manner, by modulating nutrients that would favor one cell type over another, or adding inhibitors of specific signaling pathways, more homogenous populations of cells can be generated that contain, for example, neurons, cardiomyocytes, hepatocytes, or hematopoietic cells. With addition of growth factors and signaling molecules, it is possible to further homogenize a culture to a certain cellular phenotype or to simply accelerate the natural process [7]. It has also become possible to replace supplementation of certain proteins with small chemical molecules that tend to be more cost effective. In addition to signaling molecules, cells also physically interact with each oth- er as well as their environment, highlighting the need for appropriate extracellular matrix components in order to generate the desired cell type [8]. Furthermore, through gene editing, stem cells can be programmed to overexpress particular genes at predetermined time points in order to direct differentiation genetically. Taken together, stem cell differentiation from ESCs remains an active field of research with expanding protocols that build on previous studies to expedite the process and yield purer and better-defined populations of cells.

Despite the immense potential that human ESCs hold for the future of medicine, they are also subject to some concerns. Due to their embryonic origin, there are arguments about the ethics of using cells from a human embryo for scientific discovery or medical treatment. Moreover, due to their pluripotent nature, ESC-derived cells carry a potential tumor formation risk to patients [9]. With the goal of reducing the chance of developing a tumor, stem cells are generally differentiated to a late-stage progenitor or a postmitotic cell prior to transplantation. However, since a 'rogue' pluripotent cell may still be lurking in the culture, extensive quality control must be undertaken prior to transplantation to search for and eliminate undifferentiated cells. One strategy to remove potential tumor-causing cells is to selectively induce cell death of undifferentiated cells prior to transplantation [10]. On the ethical front, the discovery of induced pluripotent stem cells (iPSCs) has reduced the demand for utilization of embryos for research [11].

iPSCs can be generated from somatic cells, such as fibroblasts, through the overexpression of four transcription factors. In the initial work, the four necessary genes (Oct-3/4, Sox2, $c-M y c$, and Klf4) were delivered to cells via retroviruses. More recently, however, it has been shown that nonviral and nongenome integrating methods of gene delivery can be used for the generation of iPSCs [12]. On a functional level, iPSCs are capable of differentiating into any other cell type in the body 
just like an ESC. Differentiation conditions to specific cell types are also the same for both cell moieties. On the genetic and protein level, iPSCs and ESCs are generally similar, and mouse iPSCs have been used to create fully formed mice [13]. iPSCs offer the distinct advantage of modeling patient diseases in vitro and providing patients with the possibility of personalized studies designed to identify the most promising treatment strategy for their particular form of the disease. Through the collection of skin biopsies, a patient's cells can be used to make iPSCs that could be expanded in culture and used to generate cell types of medical interest. In this way, a patient with glaucoma could donate a small amount of skin tissue that would be reprogrammed into iPSCs and then differentiated to RGCs that could be used for drug screening to find the optimized treatment for that particular patient.

Part of glaucoma pathophysiology is thought to involve the loss of retrograde neurotrophic transport to the RGC soma from damage to the optic nerve and/or increased IOP [14-16]. One possible approach to this problem is exogenous supplementation of neurotrophic factors (NTFs) to the retina in an effort to promote RGC function and survival. NTFs such as brain-derived NTF, ciliary-NTF, and glial cell-derived NTF all promote RGC survival in vitro and in vivo, but their delivery to the retina, and specifically RGCs, is problematic [17-20]. These NTFs would need to be administered in relatively high doses to have a positive effect, but they cannot be taken orally because the blood-retinal barrier and other factors would prevent sufficient delivery to the retina. Topical eye drops also would likely not provide sufficient NTF delivery to the retina. Local injection of NTFs into the vitreous is technically possible, and could provide a benefit, especially if combined with a slow-release formulation. However, such an approach would still involve fairly frequent injections over a prolonged period and, due to inconvenience, expense, and the risk of infection, would not be ideal. Stem cells could pro- vide an alternative and more desirable approach. For example, mesenchymal stem cells derived from the bone marrow of adult patients are known to secrete a number of NTFs, and these cells tend to travel to sites of injury as found in glaucoma [21]. Local administration of these cells would likely be required, as intravenous administration would face challenges due to the complexity of tissue homing through the body. In addition, the level of secretion of the desired factors may also not be high enough for effective treatment. However, through genetic modification of these cells in culture before injection into the vitreous, production levels of proteins can be increased. Another exciting possibility is the implantation of encapsulated cells into the eye to contain implanted cells in one place while allowing for continued release of supporting proteins [22]. Cellular encapsulation allows nutrients to enter the implant, and the implant materials can be designed so that only proteins of the desired size are able to leave the implant [23]. Through the use of well-characterized cell lines and nonviral genetic modification methods, the implanted cells should be able to safely provide a long-term supply of therapeutic proteins, growth factors, or antibodies targeting particular pathways or cellular components. Encapsulation of cells is also applicable to ESC-derived cells. ESCs could be differentiated to NTF-producing cells prior to encapsulation and then implanted into the vitreous of the eye. For example, oligodendrocyte precursor cells have been used in this way to promote RGC survival upon transplantation into rat eyes of an in vivo glaucoma model [24]. As a potential safety valve, implants can be removed or replaced at a later time as needed. Cell therapy is appealing because it allows for sustained treatment through protein supplementation, leading to a decreased need for multiple injections of NTFs.

A more sophisticated use of stem cell technology related to glaucoma involves the differentiation of stem cells into RGC-like cells. An important issue to consider in discussing stem cell-de- 
rived RGCs is to define 'what is an RGC?'. This question at first may seem silly. In the context of the retina, there is good agreement regarding the definition of an RGC. Even in the retina, however, there is disagreement between 'lumpers' and 'splitters' in terms of how many different types and subtypes of RGCs exist, with some defining greater than 20 different RGC subtypes [25]. In the context of a Petri dish in which neuronal-like cells are being derived in a nonretinal environment, the exact definition of an RGC is far less clear. Compared to other types of neurons, and especially developing neurons in culture, RGCs do not have a unique morphological appearance. There are no known RNAs or proteins whose expression is completely limited to RGCs, nor are there electrophysiological properties that can distinguish them from many other neurons. When outside of the retina, separated from their normal location and connections, the definition of what is an RGC becomes almost an existential question. To develop a reasonable operational definition, we suggest that rather than looking at just a few RGC-enriched genes as markers, it would be more meaningful to take a more system-oriented view. For example, instead of considering only a limited number of 'marker' genes, it would be desirable to consider a larger group of genes whose overall pattern of expression better define RGC identity. However, even this will be challenging, as the gene expression pattern of RGC-like cells will vary to a greater or lesser extent between different subclasses of RGCs, and between different stages of development and degeneration. Other characteristics of RGCs to consider are morphology, functional properties, and epigenetic marks. Without careful consideration, one might confuse stem cell-derived RGC-like cells with other neuronal cells such as motor neurons or CNS neurons of a related but different class. The robust characterization of stem cell-produced RGCs may also contribute to developmental research by highlighting similarities and differences between in vitro versus in vivo and human versus nonhu- man development. Therefore, stem cell derivation of RGCs presents a unique opportunity to generate a pathologically relevant cell type that can be used for translational research as well as for study of human neuronal development.

RGCs arise from common retinal progenitor cells (RPCs) that are the precursors of all retinal cell types. Despite considerable overlap in the temporal formation of different retinal cell types, RGCs are the first cell type born from RPCs, followed by horizontal cells, cone photoreceptors, amacrine cells, rod photoreceptors, bipolar cells, and Müller glia [26]. During development, RGCs are overproduced, and only those that find an appropriate target in the brain survive through a process that is thought to involve the retrograde transport of NTFs from the brain to the eye [14, 27]. Many RGCs die during this process via apoptosis, or programmed cell death [28]. Although RGC competence, or the ability for a cell to become an RGC, has been suggested to arise through a stochastic process [29], genetic studies have identified a number of genes that play a role in the establishment of RGC competence and subsequent control of RGC differentiation. One of the early active genes in retinal differentiation is Pax6. This gene is required for all retinal cell types except amacrine cells [30]. It functions upstream of the Math5 (ATOH7) transcription factor, an essential RGC cell fate regulator. Math5 is the mouse ortholog of atonal, a basic helix-loop-helix gene found in Drosophila, where it is necessary for photoreceptor formation. In vertebrates, Math5 plays a bigger role in RGC genesis. It is expressed transiently in the mouse retina, starting at embryonic day 11 (E11), peaking at E13.5, and ending at E15.5 [31]. Its expression pattern overlaps with RGC genesis [32], and mice lacking the Math5 gene have a severe reduction in RGC number $(>80 \%)$ as well as extremely thin optic nerves $[31,33]$. These knockout mice also demonstrate a disruption in their circadian rhythm, likely due to the missing intrinsically photosensitive RGCs [34]. Deletion of Math5 results in the absence of 
the RGC-enriched transcription factor $B r n 3 b$, suggesting that $B r n 3 b$ is downstream of Math5 in the RGC differentiation pathway. After differentiating from RPCs, $80 \%$ of RGCs express $\mathrm{Brn} 3 \mathrm{~b}$, and shortly thereafter the related transcription factors Brn3a and Brn3c are turned on in 80 and $20 \%$ of RGCs, respectively [35]. The knockout of $\mathrm{Brn} 3 \mathrm{~b}$ results in a 70\% loss of RGCs in adult mice, suggesting that this gene is also important for RGC survival [36]. The Isll gene is also necessary for RGC survival, as has been shown by the finding that mice in which it has been knocked out generate RGCs normally, but most of these cells undergo apoptosis soon after birth [37]. The double knockout of Brn3b and Isl1 leads to a more severe RGC phenotype, with approximately $95 \%$ death of RGCs, suggesting at least some independence in the pathways in which they function [38]. Adding to the complexity of the system, it has recently been proposed that a small subset of RGCs form from Neurod1-expressing RPCs in a pathway independent of Math5 [39]. Previously, it was thought that Math5 functioned, in part, to inhibit Neurod1, and that Neurod 1 acted to specify another cell fate entirely [40]. More recently, it has been found that Neurod1 expressed in the Math5 locus partially rescues RGC formation [41]. Again showing the complexity of the system, Math 5 replacement of Neurod 1 leads to RGC formation rather than the photoreceptor and amacrine cells that Neurod1 normally specifies [42]. These results demonstrate, as is also known from other systems, that not only the nature of the regulator expressed but also its temporal and spatial expression pattern are important in determining the functional effects of a particular transcription factor. Additionally, these studies highlight that although impressive advances have been made in elucidating the factors necessary for RGC competence and cell fate determination, the pathway to RGC differentiation remains a complex and incompletely understood process.

In addition to genes that establish competence, genes important for RGC specification are also a valuable area of research since not all progenitor cells that express Math5 eventually adopt the RGC cell fate, emphasizing that other factors are needed to fully instruct a cell down a particular path. The Sox4 and Sox 11 genes appear to be important players in this process as their double knockout results in reduction in RGCs and $\mathrm{Brn} 3 \mathrm{~b}$ expression, yet these mice possess normal Math5 expression [43]. More work still needs to be done to elucidate how these genes may function in the differentiation cascade. One way to answer some of these development questions is through ESC differentiation. Since ESCs, in general, mimic the natural developmental state, they should provide a powerful system to study the mechanism of RGC differentiation in the context of a human cell, and make possible analyses that will complement the elegant differentiation studies that have already been performed in the mouse. We anticipate that the genes discovered through these studies will be useful as RGC markers to test for RGC production in vitro. Furthermore, by manipulating this pathway using current knowledge, it may be possible to boost RGC production through overexpression or downregulation of the already identified genes.

Unfortunately for the RGC field, stem cell differentiation to retinal cells has to date largely focused upon the differentiation and production of retinal pigment epithelial and photoreceptor cells. However, since RPCs generate the different retinal cell types in a sequential chronological order [29] and since RGCs are the first-born cells in the retina during development, some of the current stem cell culture systems for producing the later borne photoreceptors should, at least at some point during differentiation, contain RGCs. In fact, the presence of such RGC-like cells has been observed, although a robust protocol for efficient RGC production from ESCs is still lacking. Nevertheless, RGCs or at least RGC-like cells have been produced from mouse as well as human stem cells. Some of the early attempts at RGC production were done through ESC co-cul- 
ture methods with mouse retinas. These studies were based on earlier work, where mouse ESCs (mESCs) grown in suspension were supplemented with Dickkopf-1 (Dkk1), Lefty A, and Activin A to favor differentiation to the retinal neuronal fate [44-47]. To achieve RGC genesis, mESCs were differentiated to an early retinal phenotype before being co-cultured with extracted mouse retinal tissue to further promote a retinal cell fate. Presumed RGC-like cells derived from the ESC cultures were found after 10 days, and a few cells were immunopositive for the RGC-enriched markers Brn3b, $\mathrm{Hu}$, and Tuj1 [48]. The stem cellderived cells expressed these three markers when found in the in vitro ganglion cell layer of the cocultured retina. This differentiation was enhanced if the retina was damaged with N-methyl-D-aspartate (NMDA) prior to co-culture. In a similar study by the same group, it was shown that mESCs that were differentiated to the early retina phase could be transplanted directly into a mouse eye [49]. Moreover, if the retina was damaged with NMDA prior to transplantation, then RGC-like cells could be readily identified by their expression of a small number of RGC-enriched markers - Tuj1, Brn3b, Pax6, Thy1.2, and NeuN. However, as discussed previously, it should be remembered that although within the retina these markers tend to be specific to RGCs, outside the retina they are expressed by a variety of different neurons. In addition, the host mice did not demonstrate a benefit in visual response as monitored by electrophysiology of visually evoked potentials, and teratomas formed in approximately $7-15 \%$ of the mouse eyes.

Co-culture methods such as those described by Aoki et al. [48] are challenging because they make control over differentiation more difficult, introduce potential contamination, and require animal tissue. In an effort to move away from coculture and toward more defined conditions, an mESC to RGC differentiation protocol was developed that relied on basic fibroblast growth factor (FGF2) and sonic hedgehog (Shh) supplementa- tion of formed embryoid bodies (EBs) in neuronal media [50]. EBs are three-dimensional aggregates of stem cells that form naturally when stem cell colonies are grown in suspension. The cells generated by this protocol expressed some RGCenriched markers, including Math5, Isl1, and Map2, by immunocytochemical analysis and Math5, Brn3b, Thy1, RPF-1, and Isl1 by RT-PCR. This protocol resulted in roughly $2 \%$ of cells that were positive for RGC genes and had an RGC-like morphology. Functionality of these cells was not explored, but transplantation of the RGC-like cells into the rat vitreous resulted in some low engraftment into the retina, including the ganglion cell layer. Yet another mouse study showed that Pax6 transfection into mESC cells could force the cells toward a neuronal phenotype, and the selection of these cells for further culture resulted in differentiation to the retinal fate [51]. Based on RT-PCR, immunofluorescence, and calcium imaging with $\mathrm{KCl}$ stimulation, the authors stated these neuronal cells to be RGC-like.

In addition to the mESC experiments described above, mouse iPSCs (miPSCs) have also been differentiated toward an RGC-like fate. In one study, EBs were generated from miPSCs and switched to neuronal media. Following Noggin and FGF2 treatment to more strongly induce a neural fate, cells were moved to laminin and poly-D-lysine-coated dishes and grown in conditioned media from rat embryonic retinal tissues from E14, a time of rat RGC genesis [52]. These stem cell cultures demonstrated upregulation of the eye field-related genes Pax6, Chx10, and $R x$, and upon growth in conditioned media began to express RGC markers, culminating after one additional month of culture in approximately 15\% of the cells expressing the RGC-enriched markers Brn3b and Rpf1 [53]. Upon culturing of these cells with either superior or inferior mouse colliculus explants, it was encouraging to note that the presumed RGCs extended processes only to the superior colliculus, which is their natural target in vivo. Furthermore, these cells were electro- 
physiologically active, displaying sodium currents. Another group targeted the formation of RGCs in a more aggressive manner. Although EBs were formed as before, the differentiation medium was supplemented with Dkk1, Noggin, and Lefty A to promote anterior neurogenesis [54]. To further specify the cells towards an RGC fate, the researchers transfected a Math5 expression plasmid into the cells prior to starting differentiation and added DAPT, a Notch signaling inhibitor, to the media. The inhibition of Notch was intended to push the cells toward neuronal differentiation [55]. A subset of RGC-enriched genes was indeed induced by this protocol, but less than $5 \%$ of the cells expressed these markers. Furthermore, the resulting cells did not integrate into a host mouse retina. Taken together, the variety of studies performed to date have shown that differentiation of mESCs and miPSCs towards RGClike cells is clearly possible, but the reported yield has remained low, resulting in very heterogeneous cultures, and the differentiation that has been achieved has generally required conditioned media from rat or mouse tissues or additional genetic manipulation. Clearly, although much has been accomplished, much still remains to be done to improve upon the available murine RGC differentiation systems.

Human stem cells have also been differentiated to retinal as well as RGC phenotypes. One of the first studies [56] took a similar approach to that described with mESCs. Cells were grown as colonies and lifted up to form EBs that were then cultured in suspension with Dkk1, Noggin, and insulin-like growth factor-1 before plating and expansion of the cultures on matrigel, a protein mixture secreted by a mouse sarcoma cell line that mimics an extracellular matrix. This protocol resulted in the production of retinal cells as based on PAX6 expression. Moreover, the presence of RGCs at 3 weeks after differentiation was supported by $\mathrm{HuC} / \mathrm{D}$, TUJ1, and neurofilament $\mathrm{M}$ immunostaining, as well as by calcium imaging studies that showed a response to glutamate and NMDA. However, only about $12 \%$ of the cells had this RGC-like profile, and more in-depth analysis was not performed. A later study, using a similar approach to differentiate mouse, monkey, and human cells to RPCs, produced cells positive for Pax6 and Isl1 as demonstrated by immunostaining. However, the generation of RGCs was not shown in their human culture system [57].

More recent publications have improved the generation of retinal neurons while also decreasing the reliance on exogenous signaling molecules for adoption of the anterior neural fate. These techniques follow the same protocol of forming EBs and then culturing them in neural promoting media followed by plating onto laminin-coated dishes. When EBs are cultured in this way, they form neural rosettes that can be manually lifted and grown in suspension to form neurospheres. This technique allows for enrichment for neuronal cells in the absence of an antibody or reporter driven selection [58]. In addition, this method has been shown to work for human iPSCs as well as ESCs. Not all rosettes develop toward a retinal progenitor lineage in this culture, with a large number of cells differentiating toward the early forebrain lineage; however, by manually separating optic vesicle-appearing neurospheres from the main population, which can be distinguished by their appearance under a light microscope, it is possible to enrich for retinal cells [59]. These cultures have endogenous expression of DKK1 and NOGGIN, and over time develop to include most neural retina cell types as well as retinal pigment epithelium. RGCs are born from these optic vesicles from day 20 to 50 as indicated by BRN3 and CALRETININ expression, but the RGCs were not further characterized in this publication because the authors were concentrating on other retinal cell types.

Optic vesicle structures represent an important advancement for recapitulating in vivo retinal development, but perhaps even more striking, optic cup-like structures can now be gener- 
ated from mouse and human ESCs [60, 61]. In this method, ESCs are aggregated into an EB-like floating structure that transforms into a hollow sphere. Over a course of a week, epithelial vesicles evaginate from this sphere and later invaginate to form a two-walled cup-like morphology with retinal progenitor gene expression. This in vitro formed optic cup contains a neural retina that is organized like its in vivo counterpart. Moreover, these 'retinas' express markers of all the appropriate cell types, including RGCs (Pax6, Brn3, calretinin). The human optic cup takes a longer time to form than its mouse counterpart, and RGC-like cells take about a month to emerge. Although as in previous studies, the RGCs in these cultures were not well characterized, with expression of only a few RGC-enriched genes providing the supporting evidence, the described retinal tissue structure produced by this method has the same retinal organization as the one seen in normal development, and this context provides further support for the observed cells being more likely to be 'real' RGCs. Unfortunately, however, like in a real retina, RGCs do not make up a large portion of the cells. In addition to the low yield, obtaining RGCs from these structures would require extracting and purifying the desired cells from the rest of the retinal cells, and efficient methods for achieving this goal have not yet been reported. Despite these limitations, these in vitro-generated human optic cups represent an invaluable resource for development studies as well as disease modeling. Furthermore, with improved RGC yield, accelerated production, and successful RGC isolation, this approach holds promise to be used for RGC generation for drug screening and cell replacement therapies. Although similar studies have not yet been published with iPSCs, such studies are underway by a number of groups [unpubl. data and pers. commun.], suggesting the possibility of using patientderived optic cups for personalized medicine. It is also interesting to note that unlike in the mouse studies, Notch inhibition by use of DAPT does not appear to increase the number of BRN3-positive cells in the generated human optic cups, although it does increase the number of CRX-positive cells, suggesting that, not surprisingly, there may be species-specific differences between mouse and human stem cells in terms of the formation of retinal structures.

The hope of many patients lies in the theoretical transplantation of lost or damaged cells in order to restore compromised function. Since the mature mammalian optic nerve does not regenerate after injury, there is hope that transplantation of stem cell-derived RGCs, or RGC precursors, into the eye may someday provide a viable approach for optic nerve regeneration and restoration of vision for patients with advanced glaucoma and other forms of optic nerve disease. However, before such an approach can be seriously considered, there are clearly many, many challenges that must be overcome. As already noted above, although partial integration of in vitro stem cell-generated RGC-like cells into a mouse retina has been reported, functional improvement has not been observed. Of course, given the need for axons to develop, reach their target, and form appropriate synapses, such a result is not surprising. It is likely that simple transplantation of cells into the eye will not be enough to restore visual function. Rather, a more ambitious multidimensional approach will be needed. Recently, administration of two compounds combined with gene therapy was shown to induce damaged RGCs to regrow their axons and restore some visual function in 10-week-old mice [62]. It is possible that treatment approaches combining cells, small molecules and/or growth factors, and bioengineering-based material supports will be able to promote nerve regeneration, especially when combined with genome engineering approaches to alter the cells prior to transplantation. In addition, stem cell-derived RGCs could also provide a substrate for screening for compounds that induce axonal outgrowth. Despite the challenging hurdles that remain for RGC transplantation into 
the retina to restore function, this avenue of research is one of the few available options for patients that have already lost considerable vision due to RGC death. Therefore, it remains an important goal of stem cell research.

In summary, stem cells remain a potentially life-changing tool for many areas of research, including the study of RGC biology and the treatment of optic nerve disease. For glaucoma, stem cells may provide a means to supply NTFs to improve RGC survival, as well as a source of RGCs to be used for drug screening and for cell replacement therapy. Although RGC differentiation from ESCs and iPSCs is clearly possible, more characterization and confirmation must be carried out in order to sufficiently establish a cellular population as one of the RGC lineage. This characterization needs to be based on physical properties such as morphology and electrophysiological responses, as well as gene expression patterns that mimic primary RGCs. Since outside the retina RGCs are in many ways not unique, it is important to array multiple parameters when assessing RGC status and purity.
These defined parameters should then be used to compare differentiation protocols in order to improve cell culture methods to raise yield and increase efficiency. Quantitative PCR analysis as well as immunostaining for multiple RGC markers is indispensable, but microarray or RNA sequencing analysis between derived cells and their embryonic counterparts should also be performed. Additionally, analysis of the DNA methylation patterns of RGC-enriched genes and their specific promoters will provide valuable information. Transplantation analysis to assess the ability of in vitro-generated RGCs to integrate into the ganglion cell layer of mouse or rat retinas will also be important. These and related studies will be essential to perform over the coming years because in vitro generation of human RGCs holds tremendous promise for elucidating developmental and disease-related signaling pathways, understanding the mechanisms of neuronal cell death in human cells, and developing novel and more effective approaches for treating patients with optic nerve disease.

\section{References}

$>1$ Quigley HA: Open-angle glaucoma. N Engl J Med 1993;328:1097-1106.

2 Nickells RW, Howell GR, Soto I, John SWM: Under pressure: cellular and molecular responses during glaucoma, a common neurodegeneration with axonopathy. Annu Rev Neurosci 2012;35: 153-179.

-3 Welsbie DS, Yang Z, Ge Y, Mitchell KL, et al: Functional genomic screening identifies dual leucine zipper kinase as a key mediator of retinal ganglion cell death. Proc Natl Acad Sci USA 2013;110: 4045-4050.

4 Quigley HA: Clinical trials for glaucoma neuroprotection are not impossible. Curr Opin Ophthalmol 2012;23:144154.

5 Sena DF, Lindsley K: Neuroprotection for treatment of glaucoma in adults. Cochrane Database Syst Rev 2013;2: CD006539.
6 Hentze H, Soong PL, Wang ST, Phillips BW, Putti TC, Dunn NR: Teratoma formation by human embryonic stem cells: Evaluation of essential parameters for future safety studies. Stem Cell Res 2009;2:198-210.

$\checkmark 7$ Amoroso MW, Croft GF, Williams DJ, O'Keeffe S, Carrasco MA, Davis AR, Roybon L, Oakley DH, Maniatis T, Henderson CE, Wichterle H: Accelerated high-yield generation of limb-innervating motor neurons from human stem cells. J Neurosci 2013;33:574-586.

8 Philp D, Chen SS, Fitzgerald W, Orenstein J, Margolis L, Kleinman HK: Complex extracellular matrices promote tissue-specific stem cell differentiation. Stem Cells 2005;23:288-296.
-9 Li JY, Christophersen NS, Hall V, Soulet D, Brundin P: Critical issues of clinical human embryonic stem cell therapy for brain repair. Trends Neurosci 2008;31: 146-153.

10 Conesa C, Doss MX, Antzelevitch C, Sachinidis A, Sancho J, Carrodeguas JA: Identification of specific pluripotent stem cell death-inducing small molecules by chemical screening. Stem Cell Rev 2012;8:116-127.

11 Yamanaka S: Induced pluripotent stem cells: past, present, and future. Cell Stem Cell 2012;10:678-684

$12 \mathrm{Yu}$ J, Hu K, Smuga-Otto K, Tian S, Stewart R, Slukvin II, Thomson JA: Human induced pluripotent stem cells free of vector and transgene sequences. Science 2009;324:797-801. 
13 Boland MJ, Hazen JL, Nazor KL, Rodriguez AR, Gifford W, Martin G, Kupriyanov S, Baldwin KK: Adult mice generated from induced pluripotent stem cells. Nature 2009;461:91-94.

14 Quigley HA, McKinnon SJ, Zack DJ, Pease ME, Kerrigan-Baumrind LA, Kerrigan DF, Mitchell RS: Retrograde axonal transport of BDNF in retinal ganglion cells is blocked by acute IOP elevation in rats. Invest Ophthalmol Vis Sci 2000;41:3460-3466.

15 Johnson TV, Bull ND, Martin KR: Stem cell therapy for glaucoma: possibilities and practicalities. Expert Rev Ophthalmol 2011;6:165-174.

16 Johnson TV, Bull ND, Martin KR: Neurotrophic factor delivery as a protective treatment for glaucoma. Exp Eye Res 2011;93:196-203.

17 Meyer-Franke A, Kaplan MR, Pfrieger FW, Barres BA: Characterization of the signaling interactions that promote the survival and growth of developing retinal ganglion cells in culture. Neuron 1995;15:805-819.

18 Ko ML, Hu DN, Ritch R, Sharma SC, Chen CF: Patterns of retinal ganglion cell survival after brain-derived neurotrophic factor administration in hypertensive eyes of rats. Neurosci Lett 2001; 305:139-142.

19 Ji JZ, Elyaman W, Yip HK, Lee VW, Yick LW, Hugon J, So KF: CNTF promotes survival of retinal ganglion cells after induction of ocular hypertension in rats: the possible involvement of STAT3 pathway. Eur J Neurosci 2004;19:265672.

20 Koeberle PD, Ball AK: Effects of GDNF on retinal ganglion cell survival following axotomy. Vision Res 1998;38:15051515.

-21 Crigler L, Robey RC, Asawachaicharn A, Gaupp D, Phinney DG: Human mesenchymal stem cell subpopulations express a variety of neuro-regulatory molecules and promote neuronal cell survival and neuritogenesis. Exp Neurol 2006;198: 54-64.

22 Sieving PA, Caruso RC, Tao W, Coleman HR, Thompson DJ, Fullmer KR, Bush RA: Ciliary neurotrophic factor (CNTF) for human retinal degeneration: phase I trial of CNTF delivered by encapsulated cell intraocular implants. Proc Natl Acad Sci USA 2006;103:3896-3901.
23 Wikström J, Elomaa M, Syväjärvi H, Kuokkanen J, Yliperttula M, Honkakoski P, Urtti A: Alginate-based microencapsulation of retinal pigment epithelial cell line for cell therapy. Biomaterials 2008;29:869-876.

$\checkmark 24$ Bull ND, Irvine KA, Franklin RJ, Martin KR: Transplanted oligodendrocyte precursor cells reduce neurodegeneration in a model of glaucoma. Invest Ophthalmol Vis Sci 2009;50:4244-4253.

25 Sanes JR, Zipursky SL: Design principles of insect and vertebrate visual systems. Neuron 2010;66:15-36.

26 Bassett EA, Wallace VA: Cell fate determination in the vertebrate retina. Trends Neurosci 2012;35:565-573.

27 Rodriguez-Tébar A, Jeffrey PL, Thoenen $\mathrm{H}$, Barde YA: The survival of chick retinal ganglion cells in response to brainderived neurotrophic factor depends on their embryonic age. Dev Biol 1989;136: 296-303.

28 Young RW: Cell death during differentiation of the retina in the mouse. J Comp Neurol 1984;229:362-373.

29 Chen Z, Li X, Desplan C: Deterministic or stochastic choices in retinal neuron specification. Neuron 2012;75:739-742.

-30 Marquardt T, Ashery-Padan R, Andrejewski N, Scardigli R, Guillemot F, Gruss P: Pax6 is required for the multipotent state of retinal progenitor cells. Cell 2001;105:43-55.

-31 Wang SW, Kim BS, Ding K, Wang H, Sun D, Johnson RL, Klein WH, Gan L: Requirement for math 5 in the development of retinal ganglion cells. Genes Dev 2001;15:24-29.

-32 Brown NL, Kanekar S, Vetter ML, Tucker PK, Gemza DL, Glaser T: Math5 encodes a murine basic helix-loop-helix transcription factor expressed during early stages of retinal neurogenesis. Development 1998;125:4821-4833.

33 Brown NL, Patel S, Brzezinski J, Glaser $\mathrm{T}$ : Math 5 is required for retinal ganglion cell and optic nerve formation. Development 2001;128:2497-2508.

-34 Brzezinski JA 4th, Brown NL, Tanikawa A, Bush RA, Sieving PA, Vitaterna MH, Takahashi JS, Glaser T: Loss of circadian photoentrainment and abnormal retinal electrophysiology in Math5 mutant mice. Invest Ophthalmol Vis Sci 2005; 46:2540-2551.
35 Badea TC, Cahill H, Ecker J, Hattar S, Nathans J: Distinct roles of transcription factors brn3a and brn3b in controlling the development, morphology, and function of retinal ganglion cells. Neuron 2009;61:852-864.

36 Gan L, Xiang M, Zhou L, Wagner DS, Klein WH, Nathans J: POU domain factor Brn-3b is required for the development of a large set of retinal ganglion cells. Proc Natl Acad Sci USA 1996;93: 3920-3925.

37 Pan L, Deng M, Xie X, Gan L: ISL1 and BRN3B co-regulate the differentiation of murine retinal ganglion cells. Development 2008;135:1981-1990.

- $38 \mathrm{Mu}$ X, Fu X, Beremand PD, Thomas TL, Klein WH: Gene-regulation logic in retinal ganglion cell development: Isl1 defines a critical branch distinct from but overlapping with Pou4f2. Proc Natl Acad Sci USA 2008; 105:6942-6947.

- 39 Kiyama T, Mao CA, Cho JH, Fu X, Pan $\mathrm{P}, \mathrm{Mu} \mathrm{X}$, Klein WH: Overlapping spatiotemporal patterns of regulatory gene expression are required for neuronal progenitors to specify retinal ganglion cell fate. Vision Res 2011;51:251-259.

$40 \mathrm{Mu}$ X, Fu X, Sun H, Beremand PD, Thomas TL, Klein WH: A gene network downstream of transcription factor Math5 regulates retinal progenitor cell competence and ganglion cell fate. Dev Biol 2005;280:467-481.

41 Mao CA, Wang SW, Pan P, Klein WH: Rewiring the retinal ganglion cell gene regulatory network: Neurod 1 promotes retinal ganglion cell fate in the absence of Math5. Development 2008; 135:33793388.

42 Mao CA, Cho JH, Wang J, Gao Z, Pan P, Tsai WW, Frishman LJ, Klein WH: Reprogramming amacrine and photoreceptor progenitors into retinal ganglion cells by replacing Neurod1 with Atoh7. Development 2013;140:541-551.

43 Jiang Y, Ding Q, Xie X, Libby RT, Lefebvre V, Gan L: Transcription factors SOX4 and SOX11 function redundantly to regulate the development of mouse retinal ganglion cells. J Biol Chem 2013; 288:18429-18438.

44 Ikeda H, Osakada F, Watanabe K, Mizuseki K, Haraguchi T, Miyoshi H, Kamiya D, Honda Y, Sasai N, Yoshimura N, Takahashi M, Sasai Y: Generation of $\mathrm{Rx}+/ \mathrm{Pax} 6+$ neural retinal precursors from embryonic stem cells. Proc Natl Acad Sci USA 2005;102:11331-11336. 
45 Meno C, Ito Y, Saijoh Y, Matsuda Y, Tashiro K, Kuhara S, Hamada H: Two closely-related left-right asymmetrically expressed genes, lefty- 1 and lefty-2: their distinct expression domains, chromosomal linkage and direct neuralizing activity in Xenopus embryos. Genes Cells 1997;2:513-524.

46 del Barco Barrantes I, Davidson G, Gröne HJ, Westphal H, Niehrs C: Dkk1 and noggin cooperate in mammalian head induction. Genes Dev 2003;17: 2239-2244.

47 Davis AA, Matzuk MM, Reh TA: Activin A promotes progenitor differentiation into photoreceptors in rodent retina. Mol Cell Neurosci 2000;15:11-21.

48 Aoki H, Hara A, Niwa M, Motohashi T, Suzuki T, Kunisada T: An in vitro mouse model for retinal ganglion cell replacement therapy. Exp Eye Res 2007;84: 868-875.

49 Aoki H, Hara A, Niwa M, Motohashi T, Suzuki T, Kunisada T: Transplantation of cells from eye-like structures differentiated from embryonic stem cells in vitro and in vivo regeneration of retinal ganglion-like cells. Graefes Arch Clin Exp Ophthalmol 2008;246:255-265.

50 Jagatha B, Divya MS, Sanalkumar R, Indulekha CL, Vidyanand S, Divya TS, Das AV, James J: In vitro differentiation of retinal ganglion-like cells from embryonic stem cell derived neural progenitors. Biochem Biophys Res Commun 2009;380:230-235.
51 Kayama M, Kurokawa MS, Ueda Y, Ueno H, Kumagai Y, Chiba S, Takada E, Ueno S, Tadokoro M, Suzuki N: Transfection with pax6 gene of mouse embryonic stem cells and subsequent cell cloning induced retinal neuron progenitors, including retinal ganglion cell-like cells, in vitro. Ophthalmic Res 2010;43:79-91.

52 Reese BE, Colello RJ: Neurogenesis in the retinal ganglion cell layer of the rat. Neuroscience 1992;46:419-429.

53 Parameswaran S, Balasubramanian S, Babai N, Qiu F, Eudy JD, Thoreson WB, Ahmad I: Induced pluripotent stem cells generate both retinal ganglion cells and photoreceptors: therapeutic implications in degenerative changes in glaucoma and age-related macular degeneration. Stem Cells 2010;28:695-703.

-54 Chen M, Chen Q, Sun X, Shen W, Liu B, Zhong X, Leng Y, Li C, Zhang W, Chai F, Huang B, Gao Q, Xiang AP, Zhuo Y, Ge $\mathrm{J}$ : Generation of retinal ganglion-like cells from reprogrammed mouse fibroblasts. Invest Ophthalmol Vis Sci 2010; 51:5970-5978.

55 Crawford TQ, Roelink H: The notch response inhibitor DAPT enhances neuronal differentiation in embryonic stem cell-derived embryoid bodies independently of sonic hedgehog signaling. Dev Dyn 2007;236:886-892.

56 Lamba DA, Karl MO, Ware CB, Reh TA: Efficient generation of retinal progenitor cells from human embryonic stem cells. Proc Natl Acad Sci USA 2006; 103 : 12769-12774.

57 Osakada F, Ikeda H, Mandai M, Wataya T, Watanabe K, Yoshimura N, Akaike A, Sasai Y, Takahashi M: Toward the generation of rod and cone photoreceptors from mouse, monkey and human embryonic stem cells. Nat Biotechnol 2008; 26:215-224.
58 Meyer JS, Shearer RL, Capowski EE, Wright LS, Wallace KA, McMillan EL, Zhang SC, Gamm DM: Modeling early retinal development with human embryonic and induced pluripotent stem cells. Proc Natl Acad Sci USA 2009;106: 16698-16703.

59 Meyer JS, Howden SE, Wallace KA, Verhoeven AD, Wright LS, Capowski EE, Pinilla I, Martin JM, Tian S, Stewart R, Pattnaik B, Thomson JA, Gamm DM: Optic vesicle-like structures derived from human pluripotent stem cells facilitate a customized approach to retinal disease treatment. Stem Cells 2011;29: 1206-1218.

60 Eiraku M, Takata N, Ishibashi H, Kawada M, Sakakura E, Okuda S, Sekiguchi K, Adachi T, Sasai Y: Self-organizing opticcup morphogenesis in three-dimensional culture. Nature 2011;472:51-56.

61 Nakano T, Ando S, Takata N, Kawada M, Muguruma K, Sekiguchi K, Saito K, Yonemura S, Eiraku M, Sasai Y: Self-formation of optic cups and storable stratified neural retina from human ESCs. Cell Stem Cell 2012;10:771-785.

62 de Lima S, Koriyama Y, Kurimoto T, Oliveira JT, Yin Y, Li Y, Gilbert HY, Fagiolini M, Martinez AM, Benowitz L: Full-length axon regeneration in the adult mouse optic nerve and partial recovery of simple visual behaviors. Proc Natl Acad Sci USA 2012;109:9149-9154.
Valentin M. Sluch

Biochemistry, Cellular and Molecular Biology Graduate Program

Johns Hopkins University School of Medicine, Wilmer Eye Institute

400 N. Broadway, Smith Building 3001-K

Baltimore, MD 21287 (USA)

E-Mail vsluch1@jhmi.edu 